University of Nebraska - Lincoln

DigitalCommons@University of Nebraska - Lincoln

Agronomy \& Horticulture -- Faculty Publications

Agronomy and Horticulture Department

2005

\title{
Farmer research: Conventional experiences and guidelines for alternative agriculture and multi-functional agro-ecosystems
}

Charles S. Wortmann

University of Nebraska-Lincoln, cwortmann2@unl.edu

A. P. Christensen

University of Nebraska-Lincoln

Keith L. Glewen

University of Nebraska-Lincoln, kglewen1@unl.edu

Terence A. Hejny

University of Nebraka-Lincoln, thejny1@unl.edu

J. Mulliken

JM Crop Consulting

See next page for additional authors

Follow this and additional works at: https://digitalcommons.unl.edu/agronomyfacpub

Part of the Plant Sciences Commons

Wortmann, Charles S.; Christensen, A. P.; Glewen, Keith L.; Hejny, Terence A.; Mulliken, J.; Peterson, J. M.; Varner, D. L.; Wortmann, S.; and Zoubek, Gary L., "Farmer research: Conventional experiences and guidelines for alternative agriculture and multi-functional agro-ecosystems" (2005). Agronomy \& Horticulture -- Faculty Publications. 538.

https://digitalcommons.unl.edu/agronomyfacpub/538

This Article is brought to you for free and open access by the Agronomy and Horticulture Department at DigitalCommons@University of Nebraska - Lincoln. It has been accepted for inclusion in Agronomy \& Horticulture -Faculty Publications by an authorized administrator of DigitalCommons@University of Nebraska - Lincoln. 


\section{Authors}

Charles S. Wortmann, A. P. Christensen, Keith L. Glewen, Terence A. Hejny, J. Mulliken, J. M. Peterson, D. L. Varner, S. Wortmann, and Gary L. Zoubek 


\title{
Farmer research: Conventional experiences and guidelines for alternative agriculture and multi-functional agro-ecosystems
}

\author{
C.S. Wortmann ${ }^{1, \star}$, A.P. Christiansen ${ }^{2}$, K.L. Glewen ${ }^{2}$, T.A. Hejny², J. Mulliken ${ }^{3}$, J.M. Peterson², \\ D.L. Varner ${ }^{2}$, S. Wortmann ${ }^{4}$ and G.L. Zoubek ${ }^{2}$ \\ ${ }^{1}$ Department of Agronomy and Horticulture and ${ }^{2}$ Cooperative Extension, University of Nebraska, \\ Lincoln, Nebraska, USA. \\ ${ }^{3} J M$ Crop Consulting, 1687 CR 24, Nickerson, Nebraska, USA. \\ ${ }^{4}$ Department of Sociology, Augustana College, Sioux Falls, South Dakota, USA. \\ *Corresponding author: cwortmann2@unl.edu
}

\begin{abstract}
Crop producers are challenged to operate profitably, use resources efficiently, meet high standards of quality and protect the environment, while sustaining rural economies and societies. Cropping systems are generally fine-tuned and improved through changes that have small effects which can often be verified only through research. The processes and successes of two farmer research projects were studied. Results of these studies, information from other sources and the authors' reflections on their own experiences were integrated to develop guidelines for the implementation of farmer research projects for alternative agriculture and multi-functional agro-ecosystems with diverse stakeholders. Surveys were mailed to 118 farmers currently or previously participating in a farmer research project, and to 15 advisors. Responses show that involvement in a farmer research project was profitable, stimulating, enjoyable and worthwhile, despite a substantial time requirement. Tillage and soil fertility research had greater impact on annual farm profit than research on other topics. Farmers and advisors emphasized the importance of the farmers' roles in identification of research topics, research planning and implementation, and interpretation of the results. Replicated trials conducted over 2 or 3 years were recognized as necessary to adequately verify practices for the corn-soybean rotation of eastern Nebraska, USA. Such trials may need to be complemented with alternative research approaches for improving alternative agriculture and multi-functional agroecosystems where knowledge about some system components is relatively scarce and there is a need to evaluate long-term effects. In conclusion, organized farmer research is an efficient means to cropping system improvement. Guidelines are given for initiation and implementation of farmer research projects.
\end{abstract}

Key words: agro-ecosystems, alternative agriculture, multi-functional, on-farm research, participatory research

\section{Introduction}

Agriculture in the US is constantly challenged to achieve greater efficiency in resource use while providing a

A contribution of the University of Nebraska Agricultural Research Division, Lincoln, NE 68583. Journal Series No. 14709. IBR 2004-03-190 EX. high-quality product, protecting the environment and sustaining rural economies and societies. Farmers face an overwhelming array of information of varying quality, veracity and applicability to their particular situations, and yet information is inadequate for some decisions. At the same time, the farmer is often the most informed person about his/her operation and is best able to judge the information needs and to apply information for making improvements $^{1-3}$. Farmers make decisions by applying 
more- or less-verified information from different sources in various ways:

- full adoption of a promoter's recommendation with little follow-up observation or evaluation;

- seeking information or advice from more- or lessobjective sources;

- testing the information through whole or partial field application with close observations; and

- testing the information through replicated or nonreplicated trials.

Alternative practices can be rejected as not feasible or profitable without field testing, but adoption may require better information, as the effects of changed practices are generally small. Replicated trials conducted over 2 or more years may be needed to verify the effects of alternative practices on yield and profitability in already fine-tuned cropping systems.

Farmer research is a methodological means of research conducted by farmers for discovery or production of information. Farmer research is generally:

- focused on priority information needs identified by, or with, the farmer or farmers;

- based on the farmer's experience and knowledge of his or her farming operation and situation, which is integrated with external knowledge; and

- conducted primarily by the farmer.

Farmer research becomes more effective when one or more of the following is true:

- farmers are knowledgeable about the situation;

- the problem is transparent to farmers, and the causal agents are easily observed and/or understood (e.g., farmers can conduct research on a new crop more easily than on a virus);

- the farming system is composed of diverse, nonconventional enterprises and their interactions;

- the agro-ecosystem is dynamic and requires responsive management;

- the research cycle is short; and

- there is institutional support for farmer research ${ }^{1-5}$.

Farmer research groups provide an opportunity to 'achieve better communication and enhanced cooperation among farmers, researchers and extension educators ${ }^{\prime}$. There is a regular flow of ideas for further improvements, a sharing of information and group participation in the interpretation of the information and its applicability. Gerber ${ }^{6}$ wrote 'It is critical that both farmers and researchers share their interpretations with each other and with the larger community'. The flow of newly discovered information to diverse stakeholders is important, as is the conveyance from farmer research groups of their information needs to public-sector scientists ${ }^{7}$.

The objectives of this research were to evaluate two farmer research projects and to develop guidelines for the implementation of farmer research projects for improving alternative agriculture and management for a multi-functional landscape ${ }^{8}$, watershed or agro-ecosystem with diverse stakeholders (referred to as multi-functional agro-ecosystems in this paper). We consider alternative agricultural systems to include various non-conventional options, such as organic farming, bio-renewable agriculture and food systems, and production of specialty crops. The guidelines were developed using information from an evaluation of the processes and successes of two on-going farmer research projects in southeastern Nebraska, and insights of the authors gained from experience with these projects and through work in eastern Africa ${ }^{3,4,9-11}$ and through study of farmer research conducted elsewhere.

\section{Project Description and Study Design}

The Nebraska Soybean and Feed Grains Profitability Project (Profitability Project) was started by educators of University of Nebraska Cooperative Extension in 1989 to enable farmer-initiated research in partnership with Cooperative Extension and private sector agronomists. Extension educators perceived a need for field-scale verification trials that address farmers' information needs and utilize their knowledge of cropping systems. In the first year, two extension educators identified and worked with 11 farmers in conducting trials. The number of farmers increased as other farmers learned of the opportunity from participating farmers and educators. The increase strained the human and equipment resources available to follow through on all research protocols. More extension educators became involved, expanding the geographic area of farmer participants. Independent crop consultants were invited to participate as advisors to design and implementation of research. Typically, about 35-40 trials have been conducted annually over an area lying in Butler, Cass, Dodge, Lancaster, Saunders and Washington counties. Each farmer selects his/her research topics. Topics are often addressed by just one farmer, but evaluated for several years. A professor emeritus of soil science assists in experimental design and data analysis on a consultancy fee basis. Farmers pay a US\$150 fee to participate in the research project, but are also offered farm management consultation as well as participation in tours and meetings organized by the Profitability Project.

The Quad County (Clay, Fillmore, Hamilton and York counties) Project grew out of planting density studies conducted by the extension educator with farmers in Hamilton county in 1998; this research was extended to the other three counties in 2000 with 20 farmers and 5 extension educators and specialists participating. Farmer recruitment was similar as for the Profitability Project. A research topic in the Quad County Project may be addressed by a single interested farmer, but most research topics are addressed by several farmers over several years.

In both projects, research is conducted as replicated trials with treatments assigned more-or-less at random to blocks, such as with alternating paired comparisons. Educators or consultants conduct statistical and economic analyses of the data. Farmers and/or their advisors present their results at 
a winter meeting to other participating, as well as to interested but non-participating, farmers, who discuss the interpretation and application of the results.

Questionnaires were mailed in February 2004 to all current or past participants in these projects, including 89 farmers of the Profitability Project and 29 farmers of the Quad County Project, to learn more of their perspectives and experiences. Questionnaires were also sent to the 15 research advisors who worked with these projects, including Cooperative Extension educators and consulting agronomists. The questionnaires used open-ended (OE) and close-ended (CE) questions to ask farmers for information on: research topics addressed $(\mathrm{OE})$; production practices changed (CE); profit gains resulting from the research (CE); successful and unsuccessful endeavors of the project $(\mathrm{CE})$; opportunities and obstacles to continued project success $(\mathrm{OE})$; reasons for participating $(\mathrm{CE})$; time requirements for participation and opportunities to simplify involvement $(\mathrm{OE})$; and reasons for farmers quitting $(\mathrm{CE})$. The questionnaires asked advisors about: successful and unsuccessful endeavors of the project and their importance (OE); opportunities and obstacles to continued success $(\mathrm{OE})$; and their reasons for participating in the project (CE). Results from close-ended questions are presented as percentages or means. Results from open-ended questions were grouped into subject-matter categories, and the number of responses per category were reported.

The results of the surveys were reported and integrated with the authors' knowledge and insights gained from these and other projects ${ }^{3,4,9-11}$, and applied to develop guidelines for implementation of farmer research projects for three crop-production situations: conventional agricultural; alternative agriculture; and multi-functional agroecosystems.

\section{Results of the Surveys}

Responses were received from 32 farmers of the Profitability Project, of which 25 are currently involved. The response rates were about $65 \%$ for active and $15 \%$ for no longer active farmers. Thirteen Quad County Project farmers responded, yielding a $45 \%$ response rate. All stated that they were currently active. Responding farmers had been involved with a farmer research project for 1-14 years, with a median of 4.5 years, and for 1-6 years, with a median of 4 years, for the Profitability Project and Quad County Project, respectively. Eleven of the 15 extension educators and consultants responded.

Farmers with the Profitability Project conducted trials to address $1-4($ mean $=2.1)$ research topics per farmer during the course of their involvement in the project. The mean for the Quad County Project, where several farmers addressed some topics, was 3.5 research topics per farmer. Research topics addressed by the 45 farmers included: 31 for planting, including row spacing, time of planting, plant density and planting speed; 30 for soil fertility management, including 9 on the use of manure or municipal biosolids; 24 for weed, insect and disease management; 13 for tillage; 3 on irrigation; and 11 for other topics. Most research topics addressed corn and soybean production.

\section{Reasons for farmer and advisor involvement}

Farmers rated profitability and being a better farmer as the most important reasons for involvement in a farmer research project (Table 1). Most enjoyed the participation and the majority responded that farmer research was a very important means to improving the area's agriculture. Most responding farmers apparently were not very concerned about neighbors' opinions of their involvement.

Advisors rated farmer research as a means to improving the area's agriculture as the leading reason for involvement (Table 2). Like the farmers, advisors enjoy the process and they believe that it helps them to be a better educator or consultant. Less important reasons were the improvement of their effectiveness and/or their businesses, and enhancement of their professional reputations.

Table 1. Importance of reasons for farmer involvement in a research project (shown as the percentage of respondents).

\begin{tabular}{lccc}
\hline Reason for participation & $\begin{array}{c}\text { Very } \\
\text { important }\end{array}$ & Important & $\begin{array}{c}\text { Not } \\
\text { important }\end{array}$ \\
\hline Nebraska Soybean and Feed Grains Profitability Project $(n=32)$ & & 13 & 3 \\
It is profitable & 84 & 16 & 3 \\
It enables better farming & 81 & 38 & 3 \\
It improves the area's agriculture & 59 & 27 & 3 \\
We enjoy it & 70 & 19 & 78 \\
It impresses neighbors & 3 & & 0 \\
Quad County Project $(n=12)$ & & 58 & 0 \\
It is profitable & 42 & 8 & 0 \\
It enables better farming & 92 & 25 & 0 \\
It improves the area's agriculture & 75 & 42 & 100 \\
We enjoy it & 58 & 0 & \\
It impresses neighbors & 0 & & \\
\hline
\end{tabular}


Table 2. Importance of reasons for extension educator and consultant involvement in a research project (shown as the percentage of respondents); $n=10$.

\begin{tabular}{lccc}
\hline $\begin{array}{l}\text { Reason for } \\
\text { participation }\end{array}$ & $\begin{array}{c}\text { Very } \\
\text { important }\end{array}$ & $\begin{array}{c}\text { Not } \\
\text { Important }\end{array}$ & $\begin{array}{c}\text { Not } \\
\text { important }\end{array}$ \\
\hline $\begin{array}{l}\text { It is a means to improving } \\
\text { the area's agriculture }\end{array}$ & 100 & 0 & 0 \\
$\begin{array}{l}\text { Helps to become a better } \\
\quad \text { educator/consultant }\end{array}$ & 90 & 10 & 0 \\
$\begin{array}{l}\text { It is enjoyable } \\
\text { Enhances my professional } \\
\text { reputation }\end{array}$ & 90 & 10 & 0 \\
$\begin{array}{l}\text { Improves effectiveness } \\
\text { or business }\end{array}$ & 60 & 20 & 10 \\
\hline
\end{tabular}

\section{Project successes}

Farmers. Based on the responses, the estimated average impact on average annual whole-farm profitability for the Profitability Project and Quad County Project, respectively, has been US\$2370 and US\$2209 for planting research,
US\$3643 and US\$5338 for tillage research, US\$5188 and US\$3842 for soil fertility, and US\$3181 and US\$2813 for pest management.

Both projects have been successful in all areas that the respondents considered important. For example, identification of more profitable farming practices, good interaction with Cooperative Extension, and improved farm profitability were rated as very important objectives and as successful by $80-100 \%$ of the respondents (Table 3 ). Project continuity was achieved and considered important. Farmer satisfaction with the farmer research projects was high, but rated as less important with the Quad County as compared to the Profitability Project. Involvement of university research was rated as more successful with the Quad County Project than with the Profitability Project, while the opposite was true for involvement of crop consultants. Both projects successfully involved agribusiness. Farmers in both groups generally reported that development of alternative cropping systems, farm safety, and influence on agricultural policy were not relevant nor important objectives of the research projects.

Table 3. Farmer assessment of importance and achievement of successes of their farmer research project (shown as the percentage of respondents and rating).

\begin{tabular}{|c|c|c|c|c|}
\hline & \multicolumn{3}{|c|}{ Success achieved $(\%)$} & \multirow{2}{*}{$\begin{array}{l}\text { Importance } \\
\text { (mean, 1-3) }\end{array}$} \\
\hline & $\mathrm{S}^{1}$ & $\mathbf{U}$ & $\mathbf{N}$ & \\
\hline \multicolumn{5}{|c|}{ Nebraska Soybean and Feed Grains Profitability Project $(n=32)$} \\
\hline Led to use of more profitable practices & 97 & 0 & 3 & 2.9 \\
\hline Good interaction with extension & 94 & 6 & 0 & 2.7 \\
\hline Improved farm profitability & 84 & 6 & 9 & 2.8 \\
\hline Improved farmer satisfaction & 84 & 0 & $13^{2}$ & 2.6 \\
\hline Project continuity & 78 & 6 & 13 & 2.5 \\
\hline Involved university research effectively & 75 & 6 & 19 & 2.4 \\
\hline Involved consultants effectively & 72 & 9 & 16 & 2.4 \\
\hline Enabled farmer innovativeness & 69 & 0 & 28 & 2.3 \\
\hline Involved agri-business effectively & 53 & 6 & 38 & 2.2 \\
\hline $\begin{array}{l}\text { Led to development of alternative cropping } \\
\text { systems }\end{array}$ & 25 & 6 & 81 & 1.6 \\
\hline Improved farm safety & 25 & 0 & 72 & 1.6 \\
\hline Influenced agricultural policy formulation & 16 & 6 & 75 & 1.6 \\
\hline \multicolumn{5}{|l|}{ Quad County Project $(n=12)$} \\
\hline Led to use of more profitable practices & 83 & 8 & 8 & 3.0 \\
\hline Good interaction with extension & 92 & 8 & 0 & 3.0 \\
\hline Improved farm profitability & 75 & 17 & 0 & 3.0 \\
\hline Improved farmer satisfaction & 83 & 0 & 17 & 2.5 \\
\hline Project continuity & 67 & 0 & 17 & 2.5 \\
\hline Involved university research effectively & 83 & 0 & 8 & 2.7 \\
\hline Involved consultants effectively & 50 & 17 & 33 & 2.3 \\
\hline Enabled farmer innovativeness & 92 & 0 & 8 & 2.7 \\
\hline Involved agri-business effectively & 58 & 8 & 17 & 2.3 \\
\hline $\begin{array}{l}\text { Led to development of alternative cropping } \\
\text { systems }\end{array}$ & 42 & 25 & 42 & 1.8 \\
\hline Improved farm safety & 25 & 8 & 58 & 2.0 \\
\hline Influenced agricultural policy formulation & 25 & 0 & 67 & 1.8 \\
\hline
\end{tabular}

${ }^{1}$ Success (S), unsuccessful (U), not relevant (N), very important (3), less important (2), not relevant (1).

2 Percentages do not always total $100 \%$ as not all farmers responded to some questions. 
Additional successes rated very important by one farmer each included good interaction with other farmers and university faculty, assistance in decision making, accelerated technology adoption, improved irrigation efficiency and a better understanding of soil fertility. The only additional 'unsuccessful endeavors' reported were that not all trials produced positive information and that replicated tillage trials are difficult for farmers to conduct.

Extension educators and consultants. Advisors most frequently identified the following as successes: the reputation of Cooperative Extension is enhanced with farmers and information was gained on topics where formal research was inadequate or lacking (e.g., long-term effects of lime application, pollen drift and yield lag with Bt corn, and chloride application) (Table 4). Successes mentioned by four advisors each were increased farmer participation and farmer adoption of practices as a result of the research findings. Three respondents each reported the following successes: farmers better understand and learn to conduct their own agronomic research ('Each of the farmers has learned that they can gather information that can be used on their site; ... [We can] check to see if the claim is a real or imagined return to the farmer.'); and farmer willingness to share their information ('The level of discussion and camaraderie is higher than any large group I have encountered in agriculture.').

The most frequently mentioned unsuccessful endeavor was poor implementation of some trials. Two advisors each mentioned the following: educational tours and meetings often are not held or are poorly attended, and Cooperative Extension specialists are inadequately involved: "We need to do a better job of connecting growers and their on-farm comparisons with university faculty' and 'We don't get much interest from specialists

Table 4. Successes achieved and not achieved identified from an open-ended question by 11 extension educators and consultants who assist in farmer research; number that named a success achieved or not achieved.

\begin{tabular}{ll}
\hline & Number \\
\hline $\begin{array}{l}\text { Success achieved } \\
\text { The reputation of Cooperative Extension }\end{array}$ & 6 \\
$\quad$ with farmers is enhanced & 5 \\
Addressed topics lacking university research & 4 \\
Farmer participation has increased & 4 \\
Farmers adopted better practices & 3 \\
Farmers better understand agronomic research & 3 \\
Farmers have learned to conduct their & \\
$\quad$ own research & 3 \\
Great sharing of information by farmers & \\
Success not achieved & 4 \\
Too many trials are not well implemented & 2 \\
Extension specialists are not adequately & \\
$\quad$ involved & 2 \\
Educational tours and meetings often not & \\
$\quad$ held or are poorly attended &
\end{tabular}

to be involved with the group'. Other failures to achieve full success were identified: too few of the research ideas come from farmers; farmers often lose interest; not much mutual learning among farmers on yield mapping; and inadequate publication and dissemination of the results.

\section{Successful initiation of a farmer research project}

Advisors identified several elements important to the successful start-up of farmer research projects. Starting with the right farmers was seen as essential to successful initiation: 'farmers who are respected in the community and who are willing to share/promote/tell the story to their peers'. In addition, genuine involvement of farmers is important. Farmers need to identify the research priorities: 'Growers need to identify comparisons that are relevant to their operation' and 'The important elements ... the ability of the farmer to choose the type of on-farm research that he or she would like to do'. Farmers also need to be involved in planning the research and fully understand the protocol: 'Another important detail is the grower's understanding of the plot protocol and the importance of proper planting and harvesting'.

Advisors identified the importance of their own role, as well as extension boards, and administrative support. One observed that it was a must to find 'Extension Educators who are willing to put in the necessary time'. Another identified the importance of time management and giving the project adequate priority: 'We all have to manage our time and work on priority issues. For us, this is a priority effort!' Supportive extension boards are vital: 'Supportive Extension Boards are a must ... they must see the benefits to the producers ... to know how the data will be shared'. Further, administrative recognition that the project is a time-intensive long-range investment for advisors is also crucial ' ... some administrators didn't see the big picture in the early days and I believe I was penalized for spending so much time with such a small group ... you have to invest time to get these things going and the pay-off isn't always immediate'.

Successful implementation and continuation can be compromised by rapid expansion, excessive time demand, and inadequate communication. One advisor commented:

The larger the group gets, the harder it is to keep everyone focused on the goals of the group ... the interaction among farmers ... begins to fade. Also, as the group expands it becomes more difficult to have close oversight and you need to trust more people to do things correctly. The approach we took is very time consuming for the educators involved, so it has to be a priority for them, too.

Too many research topics that do not yield information useful for increased profit can cause loss of interest: 
'Another possible pitfall is a grower selects a comparison that does not have a significant impact on the profitability of their farming operation'.

\section{Opportunities and obstacles to continued and greater success}

Farmers responded with enthusiasm when asked to identify opportunities to make the research project more successful (Table 5). Opportunities were described as 'endless and unlimited'. Information needs driven by continued technological developments were recognized as an opportunity to continued success: ' . . . with all the new technology in agriculture, there is no shortage of ideas'; 'Trying new ideas and using a group makes it easier to sort out new thought on a large scale' and 'Success is limited only by our imagination, so many things are out there and agriculture is changing so fast. We have to try and stay with or ahead'.

Farmers identified enhancement of farmer research skills, critical thinking and willingness to share information as opportunities for greater success (Table 5): ‘ . . building on what we have done', '... farmer ability to conduct research; willingness to share information' and 'Working with critical thinkers, growers and consultants is addictive and a formula for professional success'. The support of advisors was frequently mentioned as an opportunity to generate continued success. Opportunities to broaden the impact of farmer research were identified: 'set up a webbased clearinghouse to disseminate the research results and

Table 5. Opportunities and obstacles to continued and increased success of farmer research projects; number that named an opportunity or obstacle in response to open-ended questions.

\begin{tabular}{|c|c|c|}
\hline & $\begin{array}{c}\text { Farmers } \\
(n=44)\end{array}$ & $\begin{array}{c}\text { Advisors } \\
(n=11)\end{array}$ \\
\hline \multicolumn{3}{|l|}{ Possible opportunities to greater success } \\
\hline The need for information & 19 & 3 \\
\hline $\begin{array}{l}\text { Farmer ability to conduct } \\
\text { research }\end{array}$ & 5 & \\
\hline $\begin{array}{l}\text { Willingness to share } \\
\text { information }\end{array}$ & 3 & 2 \\
\hline $\begin{array}{l}\text { Support of extension } \\
\text { educators }\end{array}$ & 2 & 3 \\
\hline Support of consultants & & 4 \\
\hline Enhanced critical thinking & 3 & 1 \\
\hline Building on our accomplishments & 3 & \\
\hline $\begin{array}{l}\text { Cooperation in identifying good } \\
\text { research topics }\end{array}$ & 2 & 1 \\
\hline Research topic diversity & & 2 \\
\hline $\begin{array}{l}\text { Statewide implementation of farmer } \\
\text { research projects }\end{array}$ & & 2 \\
\hline \multicolumn{3}{|l|}{ Possible obstacles to continued success } \\
\hline Insufficient time for implementation & 16 & 4 \\
\hline Lack of funding & 8 & 2 \\
\hline Loss of interest & 4 & 2 \\
\hline
\end{tabular}

to promote farmer research throughout the State'. Greater farmer and consultant involvement in the project leadership was suggested.

Time and expenses required for good project implementation were the most frequently mentioned obstacles to continued success (Table 5): 'Costs involved to the farmer, mainly time and extra work' and 'Time and energy are our limiting factors'. However, respondents warned against seeking industry support for the research: 'Keep . . . industry out of sponsoring, as they will taint the process'. Loss of interest in the research was another obstacle mentioned by several: 'Being content to live on the past successes'; and 'Farmers not seeing much value in what they are doing'.

\section{Improving project implementation}

Farmers were asked to identify the most time-consuming parts of their involvement in the project. Planting and harvesting the replicated trials, and ensuring proper application of the treatments, were most frequently cited as time consuming (Table 6) but recognized as needed and worthwhile investments: 'Time is just a part of it. Whether it is coming up with the ideas or implementing, it takes time'. Advisors also mentioned time constraints as limiting implementation. Norman et al. ${ }^{12}$ also found this to be true for county agents in Kansas: 'Having far too many duties was by far the most important constraint' to more and better implementation of on-farm trials and demonstrations.

Two-thirds of the farmers who answered the question 'What could be done to simplify your involvement in the Project?' responded that no further simplification was needed: 'I'm not sure I want it simplified. I enjoy it or I wouldn't do it'. Two responses suggested simpler trials: 'Simpler plot designs' and 'Probably should have cut the size in half'. Two suggested that harvesting of trials can be eased with yield monitors: 'It has helped to use grain monitors on combine'. Following the protocol may ease trial implementation: 'Make sure I follow instructions correctly'. Most farmers ( $81 \%$ ) answered 'just right' to the question 'Do you feel your level of involvement is too much, just right or too little?' Four replied 'too little' and one replied 'too much'.

The time requirement for conducting the research and satisfaction with the current farming practices were the

Table 6. Time-consuming factors in conducting farmer research identified by participating farmers; frequency of mention in response to an open-ended question, $n=44$.

\begin{tabular}{lc}
\hline Time consuming factors & Frequency \\
\hline Planting replicated trials & 16 \\
Harvesting replicated trials, collecting data & 15 \\
Applying the treatments & 12 \\
Paperwork, meetings, reporting & 4 \\
Planning trials & 2 \\
\hline
\end{tabular}


Table 7. The importance of reasons for farmers quitting or not becoming involved in the research project.

\begin{tabular}{lcc}
\hline & $\begin{array}{c}\text { Profitability } \\
\text { Project } \\
(\boldsymbol{n}=\mathbf{3 2})\end{array}$ & $\begin{array}{c}\text { Quad } \\
\text { County } \\
(\boldsymbol{n}=\mathbf{1 2})\end{array}$ \\
\hline Research required too much time & $2.6^{1}$ & 2.7 \\
$\begin{array}{l}\text { Farmer was content with the } \\
\quad \text { practices currently used }\end{array}$ & 2.4 & 2.3 \\
$\quad$ Trials were difficult to implement & 2.1 & 2.5 \\
Farmer became less involved in & 2.1 & 1.8 \\
$\quad$ crop production, e.g., retired & & \\
Farmer preferred to rely on other & 2.0 & 2.2 \\
$\quad$ information sources & 1.5 & 1.5 \\
Farmer preferred not to share & & \\
$\quad$ information & & \\
\hline
\end{tabular}

${ }^{l}$ Very important (3), less important (2), not important (1).

most important reasons for farmers quitting or not becoming involved (Table 7). Also important were farmer retirement and difficulty in implementing the trials. Lack of farmer willingness to share information with other farmers was not an important reason for non-involvement.

\section{Guidelines for Implementing Farmer Research}

The impact on farm profitability, the continuity, and the enthusiasm of participants indicate that both farmer research projects are successes and that similar efforts are needed throughout Nebraska (Tables 3 and 4). In this section, insights from farmer and advisor responses and authors' experiences are applied to develop guidelines for the implementation of farmer research projects, and to suggest means for improving existing farmer research projects.

Some of the guidelines may be applicable to farmer research for improving conventional cropping systems, alternative agriculture, and multi-functional agro-ecosystems (Table 8). Each of the guidelines presented in these tables is based on the survey results, with the exception of guideline \#13 which is based on the authors' experiences. Additional guidelines are given for alternative agriculture and multi-functional agro-ecosystems.

\section{Farmer research for alternative agriculture}

Alternative agriculture is the largest growth sector in US agriculture and the organic industry alone grew at a rate of $24 \%$ for much of the $1990 \mathrm{~s}^{13}$. Conventional and alternative systems may overlap significantly, in that conventional farmers often strive to increase bio-renewability or to diversify with specialty crops or products.

Private and public sector research has more frequently addressed conventional than alternative agricultural enterprises. Experience and information about a component of an alternative agriculture enterprise, e.g., a new crop under certain growing conditions, is relatively scarce compared to components of conventional agriculture. Therefore, alternative agriculture, compared to conventional cropping systems, may be able to achieve relatively large increases in profitability with a change of practices. Replicated, onfarm trials have a role here, as do less demanding research procedures. The farmer may need to do preliminary investigations to detect large effects before conducting more time-consuming replicated trials. Situations for discovery of information may be created, either in the field or through some form of simulation (e.g., crop growth models), which may yield adequate information to reject possible practices, plan other research, or possibly adopt a practice. Replicated trials conducted over time will be necessary to evaluate the success of fine-tuning the process.

In addition to the widely applicable guidelines in Table 8 , the following guidelines for alternative agriculture were derived largely from the authors' reflections on their experiences and other information on involvement of farmers in research.

1. Consider the diversity of the participating farmers. Are enough interests shared to justify cooperation in farmer research? Are enough farmers interested to have specialized research groups, e.g., for organic farming or acreage owners?

2. Less-demanding research approaches in addition to replicated field trials may be valuable for screening alternative crops and practices providing sufficient information to reject some options. These might be 'discovery situations', where one or more practice is applied, or a new crop planted, to a part of or to the whole field, without replication, and maybe without a direct comparison, but with careful observation of crop performance.

3. Fine-tuning of production systems is likely to require that replicated trials are conducted to evaluate small effects with confidence.

4. Tours to visit the farms and research of participating farmers may be more important than with farmer research for conventional agriculture, for sharing of information, for participation in observation and interpretation of the observations, and for generating ideas for opportunities and information needs.

A limitation with alternative agriculture is that it often serves small niche markets for which supply can easily exceed demand. Entrepreneurs may, therefore, be reluctant to share information with other interested parties.

\section{Farmer research for multi-functional agro-ecosystems}

Diverse stakeholders have a growing interest in multifunctional agro-ecosystems where numerous land uses are concerns, e.g., crop and animal production, flood control and water quality protection, water and field recreation, tourism and aesthetics, and education. Diverse information is necessary to optimize resource management. 
Table 8. Guidelines relevant for initiation and implementation of farmer research projects for conventional and alternative agriculture, and for multi-functional agro-ecosystems.

1. Introduce the idea of a farmer research project to likely farmer participants and county extension boards, with the assistance of an extension educator, consultant and farmers from an established farmer research project

2. Start small, with an adequate resource base, for a good start and later expansion. The ideal size in terms of participating farmers and geographic area was not addressed, but up to 40 farmers from a 4 or 5 county area has proven successful

3. Initial leadership by one or more extension educators who are committed to farmer research may be essential. Equally important is the involvement of farmers who are motivated to invest the time and other resources for successful implementation of research, able to promote the work with other farmers and, eventually, assume leadership roles in the project

4. Identify and prioritize research topics, and plan research, with individual farmers, but also in groups to stimulate innovation and cooperation among farmers

5. Initially, select topics of much interest and with a high probability of yielding profitable information, as such information will stimulate enthusiasm

6. Communicate clearly about the purpose and experimental processes of farmer research. Some basic introduction to experimental design and to statistical and economic analysis is needed, including the roles of replication and randomization, minimizing experimental error, repetition over years and/or farms, and probability in declaring an effect significant. This information may need to be repeated over time

7. Good implementation of trials is very important to success

8. Annual meetings of participants to discuss results are valuable to achieve full interpretation of the results, stimulate research ideas and disseminate information

9. Effectively disseminate research results beyond project participants, for example through a web site and with media reports

10. Enable interaction between existing farmer research projects

11. Involve, and provide feedback to, university research and extension specialists. Bring independent consultants, as well as agri-business personnel, into the process, but with clear understanding of their roles

12. Avoid financial support that might threaten the unbiased nature of the research

13. While not directly evaluated in this study, the role of tours, field days and informational meetings with a focus on farmer research may stimulate enthusiasm

14. Employ advanced technology as it becomes feasible, e.g., remote sensing, soil property mapping, yield mapping

Stakeholders and participants in such agro-ecosystems are likely to be diverse, including farmers, townspeople, natural resource managers, and possibly educators and/or developers/promoters of tourism and recreation. Information, experience, perspectives and interests of stakeholders in multi-functional watershed management are likely to vary considerably ${ }^{2}$. 'Opportunities for progress with an agro-ecosystem or multi-functional landscape approach may be enhanced with community involvement rather than limiting the process of opportunity and problem identification, information gathering or research, and decision making to the land managers. ${ }^{12}$ This will require a collective vision and focus on outcomes and a process of 'constant learning and adaptation to new insights and constantly changing conditions by all stakeholders' ${ }^{14}$. Knowledge sharing needs to be integrated with knowledge generation $^{5}$.

Most of the guidelines given above for conventional and alternative agriculture situations may apply to stakeholder research for improved multi-functional agro-ecosystems. Additional elements with involvement of a good representation of stakeholders may include: a vision statement; an inventory of resources; and prioritization of opportunities and needs.

Farmer research for multi-functional agro-ecosystem management may involve several approaches with more or less robust research methods, but with involvement of diverse stakeholders with a shared vision and a clear and coherent common agenda ${ }^{15}$, including:
- landscape transects by groups of stakeholders to observe existing land uses and speculation on alternative uses for different purposes;

- study of existing components of the landscape (e.g., a segment of riparian area in a watershed) which may include use of remote sensing and Geographic Information Systems;

- creation of 'situations of discovery' in the field or using models;

- replicated field trials; and

- application of the triangulation principle, linking together multiple sources of information and methods $^{5,15}$.

Computer simulations and learning from other watersheds may be useful. The effects of some potential practices will occur too far into the future for replicated field trials to be feasible. Public-sector researchers may be challenged to move from approaches of producing information to apply in farming or agro-ecosystems, to discovery approaches of learning from farmers and their systems, coupled with collaboration in farmer research ${ }^{16}$.

\section{Conclusions}

Farmers and advisors found that participation in a farmer research project is profitable and otherwise rewarding, despite considerable investment of their time at busy times of the year. Their responses indicated a need for similar research projects throughout the state of Nebraska, and 
provided information that is directly applicable to the initiation and implementation of such projects for conventional crop production systems. This information was combined with information and experiences from other farmer research situations to develop guidelines to the implementation of farmer research for alternative agriculture systems and for multi-functional agro-ecosystems with diverse stakeholder involvement.

\section{References}

1 Bentley, J.W. 1992. Alternatives to pesticides in Central America. Applied studies in local knowledge. Culture and Agriculture 44:10-31.

2 McDougall, C. and Braun, A. 2003. Navigating complexity, diversity and dynamism: reflections on research for natural resource management. In B. Pound, S.S. Snapp, C. McDougal and A. Braun (eds). Uniting Science and Participation: Managing Natural Resources for Sustainable Livelihoods. Earthscan, UK and IRDC, Toronto, Canada. p. 20-47.

3 Fujisaka, S., Wortmann, C., and Adamassu, H. 1997. Resource poor farmers with complex technical knowledge in a high risk system in Ethiopia. Can research help? Journal of Farming Systems Research and Extension 6:1-14.

4 Nielson, F., Farley, C., and Wortmann, C. 1997. Opportunities and constraints for farmer participatory research for technology development and diffusion. In J.M. Kang'ara, A.J. Sutherland, and M. Gethi (eds). Participatory Dryland Agricultural Research of Mount Kenya. Kenya Agricultural Research Institute and British Department for International Development, Nairobi, Kenya. p. 2-15.

5 Ashby, J. 2003. Introduction: uniting science and participation in the process of innovation-research for development. In B. Pound, S.S. Snapp, C. McDougal, and A. Braun (eds) . Uniting Science and Participation: Managing Natural Resources for Sustainable Livelihoods. Earthscan, UK and IRDC, Toronto, Canada. p. 1-19.

6 Gerber, J.M. 1992. Farmer participatory research model for adaptive research and education. American Journal of Alternative Agriculture 7:118-121.
7 Lacy, W.B. 1996. Research, extension, and user partnerships: models for collaboration and strategies for change. Culture and Human Values 13:33-41.

8 Francis, C., Salomonsson, L., Lieblein, G., and Helenius, J. 2004. Serving multiple needs with rural landscapes and agricultural systems. In D. Rickerl and C. Francis (eds). Agroecosystems Analysis. American Society of Agronomy, Madison, WI. p. 147-165.

9 Fischler, M. and Wortmann, C.S. 1999. Green manure research in eastern Uganda-a participatory approach. Agroforestry Systems 47:123-138.

10 Fischler, M., David, S., Farley, C., Ugen, M., and Wortmann, C. 1996. Applying farmer participation research methods to planning agricultural research: experiences from eastern Africa. Journal of Farming Systems Research and Extension 6(1):37-54.

11 Wortmann, C.S., Kaizzi, C.K., and Fischler, M. 1999. Farmers' experimentation on green manure/cover crops: A component of participatory research for improvement of Ugandan farming systems. In S. Fujisaka (ed.). Systems and Farmer Participatory Research: Developments in Natural Resource Management. CIAT, Cali, Colombia. p. 118-127.

12 Norman, D., Freyenberger, S., and Schurle, B. 1997. County extension agents and on-farm research work: results of a Kansas survey. Journal of Extension 35. Available on-line at http://www.joe.org/joe/1997october/a4.html (verified 20 July 2004).

13 Creamer, N.G. 2000. Organic farming systems. Available online at http://www.ncsu.edu/organic_farming_systems.html (verified 22 July 2004).

14 Flora, C.B. 2004. Community dynamics and social capital. In D. Rickerl and C. Francis (eds). Agroecosystems Analysis. American Society of Agronomy, Madison, WI. p. 93-107.

15 Vernooy, R. and McDougall, C. 2003. Principles for good practice in participatory research: reflecting on lessons from the field. In B. Pound, S.S. Snapp, C. McDougal, and A. Braun (eds). Uniting Science and Participation: Managing natural resources for Sustainable Livelihoods. Earthscan, UK and IRDC, Toronto, Canada. p. 113-141.

16 Thornley, K. 1990. Involving farmers in research: a farmer's perspective. American Journal of Alternative Agriculture 5:174-177. 